EGU21-5121

https://doi.org/10.5194/egusphere-egu21-5121

EGU General Assembly 2021

(c) Author(s) 2021. This work is distributed under

the Creative Commons Attribution 4.0 License.

\title{
The MINETRAIN project: Lifelong Learning opportunities for mining industry related professionals in real-life underground mining conditions; Dealing with the aftermath of two innovative pilot courses
}

George Barakos ${ }^{1}$, Kirsi Luolavirta ${ }^{2}$, Jari Joutsenvaara², Saija Luukkanen ${ }^{2}$, Hannah Julia Puputti ${ }^{2}$, and Helmut Mischo ${ }^{1}$

${ }^{1} \mathrm{TU}$ Bergakademie Freiberg, Germany

${ }^{2}$ Oulu Mining School, University of Oulu, Finland

Being at the phase of entering the new digital era, the mining industry is constantly facing challenges utilizing the introduction of data-oriented and multi-criteria decision-making concepts, demand for real-time solutions and need for experienced staff. Hence, lifelong updating of knowledge and skills of mining experts has become increasingly important and recognized worldwide as a challenge for developing a sustainable mining sector. It is also well acknowledged that an interdisciplinary understanding of mining professionals over the integrated mine value chain is expected to optimize the efficiency of operations and in turn, enhance the feasibility of mining projects. Given also the nature of the vast majority of mining activities, practical know-how is of great importance. There are, however, very few opportunities around the world for hands-on training in real mining conditions, and even less so at actual mine sites.

Hence, the idea of transforming abandoned or closing mines into training facilities is becoming more and more attractive among mining industry professionals, academics and researchers. Nevertheless, the theory is far from practice, and such an endeavour is by no means easy. In this concept, the Pyhäsalmi Cu-Zn Mine, in northern Finland is shortly to cease its operations. New activities are being investigated for the post-usage of the mine site. This in mind, Callio has been established as an umbrella organization to offer opportunities for business, development and research projects in the existing unique mine environment. Accordingly, the MINETRAIN project was launched in 2018 to investigate the possibility of utilization of the Pyhäsalmi Mine site for the education of mining experts and students. As a training and educational facility, the Pyhäsalmi mine will provide a globally unique environment, with training possibilities covering topics over the entire Mine Life Cycle; from exploration to mine closure.

To test the feasibility of Pyhäsalmi mine as an educational and training site, two pilot training courses have been developed during the last two years in the context of MINETRAIN, namely Mine Life Cycle and Digital Life of a Mine. The participation was tremendous, and the feedback received from the trainees has been highly positive; the obtained worldwide attraction strongly implies a great interest among mining professionals in practical education. Hence, in this paper, the 
challenges faced and the lessons learnt from the organization of these pilot courses are discussed with respect to the viable transition of Pyhäsalmi mine to an educational and training underground facility. 